\title{
Investegation of Factors Associated with Tcd4 + Lymphocyte Count Change and Survival Of HIV+ Patients Using Joint Model with Longitudinal and Survival Measurements
}

\author{
Sayeh Motevaseli Darab ${ }^{1}, \underline{\text { Afshin Almasi }}{ }^{2}$, Soodeh Shahsavari $^{3}$, Ebrahim Shakiba ${ }^{4}$, Elham Madreseh ${ }^{5}$ \\ 1. MSc Biostatistics, Department of Biostatistics, School of Public Health, Student's Research Committee, Kermanshah \\ University of Medical Science, Kermanshah, Iran, ORCID ID: 0000-0001-9459-9840. \\ 2. Assistant Professor of Biostatistics, Department of Biostatistics, School of Health, Cardiovascular Research Center, \\ Research Institute for Health, Kermanshah University of Medical Science, Kermanshah, Iran., (Corresponding Author), Tel: \\ 083-38262052, Email: afalmasa@gmail.com, ORCID:0000-0001-7698-9087. \\ 3. Assistant Professor of Biostatistics, Department of Health Information Technology, Faculty of Para Medicine, \\ Kermanshah University of Medical Sciences, Kermanshah, Iran. ORCID ID: 0000-0002-5282-0030. \\ 4. Associate Professor of Clinical Biochemistry, Department of Biochemistry, School of Medicine, Social Development and \\ Health Promotion Research Center, Research Institute for Health, Kermanshah University of Medical Sciences, Kermanshah, \\ Iran. ORCID ID: 0000-0002-9603-4293. \\ 5. PhD Student in Biostatistics, Department of Epidemiology and Biostatistics, School of Public Health, Tehran University \\ of Medical Sciences, Tehran, Iran. ORCID ID: 0000-0002-6987-2179.
}

\begin{abstract}
Background and Aim: Human immunodeficiency virus (HIV) is now a major global health problem. The aim of this study was to determine factors affecting the change in TCD4+ lymphocyte count and survival of HIV patients simultaneously in Kermanshah Province, using a joint model for longitudinal and survival time measurements.

Materials and Methods: In this retrospective cohort study we extracted data of 614 HIV+ patients receiving antiretroviral therapy from the Registry of Behavioral Disease Counseling Center of Kermanshah Province from 2001 to 2018. Data included variables of longitudinal TCD4+ and survival of patients (time interval from HIV diagnosis to death) as response. Then, using a joint model, the relationship between TCD4+ and the survival of patients was determined. Data analysis was performed using R (3.4.3) software package JM. $\mathrm{P}<0.05$ was considered significant.
\end{abstract}

Results: In the joint model, sex, age at the time of diagnosis, marital status, history of addiction, education level, time, and presence of tuberculosis had a significant relationship with TCD4+ lymphocyte count $(p<0.05)$. Tuberculosis $(H R=2.624)$ was an effective risk factor for death of HIV patients $(p<0.001)$. There was a significant relationship between the two responses $(p<0.001)$ so that 1 -unit decrease in the number of TCD4+ lymphocytes led to a $36.5 \%$ increase in the risk of death over time.

Conclusion: Since HIV+ patients are exposed to the risk of development of tuberculosis, a decrease in the number of TCD4 + lymphocytes may be a good prognostic indicator for death in HIV patients.

Keywords: Joint model, Longitudinal measurements, Survival, HIV, TCD4+

Received: Oct 22, $2019 \quad$ Accepted: Sep 29, 2020

How to cite the article: Sayeh Motevaseli Darab, Afshin Almasi, Soodeh Shahsavari, Ebrahim Shakiba, Elham Madreseh. Investegation of factors associated with TCD4 + lymphocyte count change and survival of HIV+ patients using joint model with longitudinal and survival measurements. SJKU 2021;26(4):59-68.

Copyright (C) 2018 the Author (s). Published by Kurdistan University of Medical Sciences. This is an open access article distributed under the terms of the Creative Commons Attribution-Non Commercial License 4.0 (CCBYNC), where it is permissible to download, share, remix, transform, and buildup the work provided it is properly cited. The work cannot be used commercially without permission from the journal 


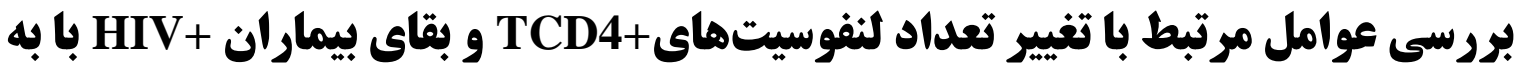

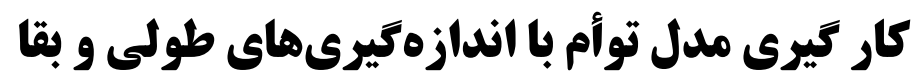

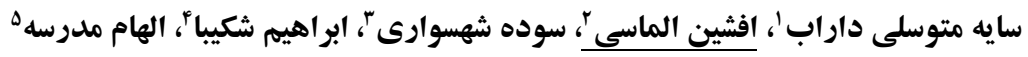

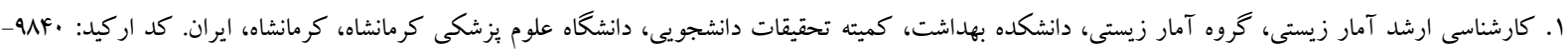
r. استاديار آمار زيستى، گروه آمار زيستى، دانشكده بهداشت، مركز تحقيقات قلب و عروق، يُزوهشكده سلامت، دانشگاه علوم بز شكى كرمانشاه، كرمانشاه ايران (نويسنده

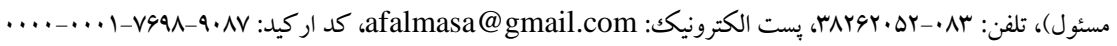

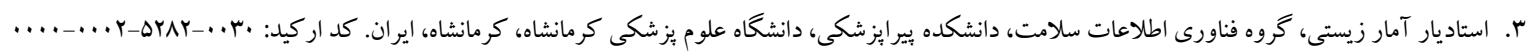

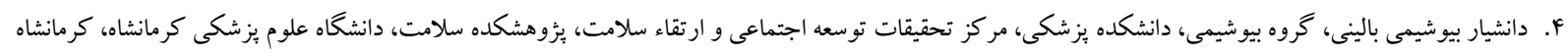

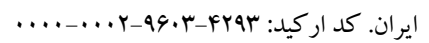

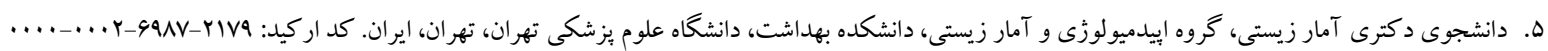

جكيده

زمينه و هدف: ويروس نقص سيستم ايمنى انسانى (HIV) در حال حاضر يك مشكل مهم بهداشت جهانى است. اين مطالعه با هدف تعيين همزمان عوامل مؤثر بر تغيير تعداد لنفوسيتهاى TCD4 و بقاى بيماران مبتلا به HIV در استان كرمانشاه با

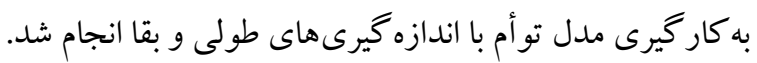

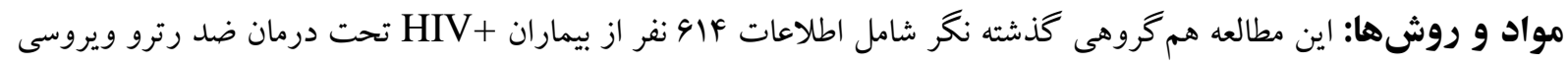

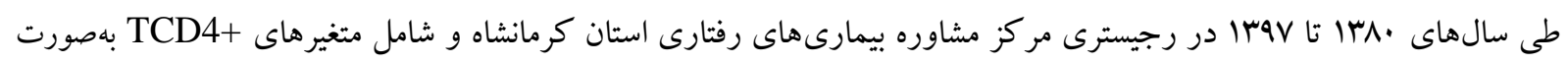

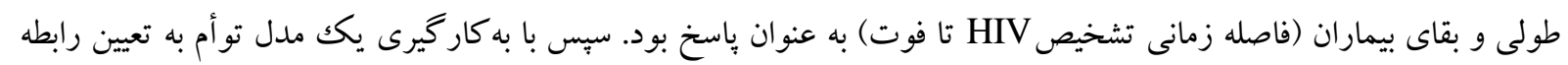

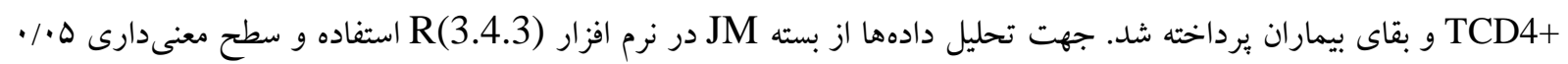
در نظر گرفته شد.

يافته ها: در مدل توأم، جنسيت، سن تشخيص، وضعيت تأهل، سابقه اعتياد، سطح تحصيلات، زمان و بيمارى سل ارتباط معنىدار با

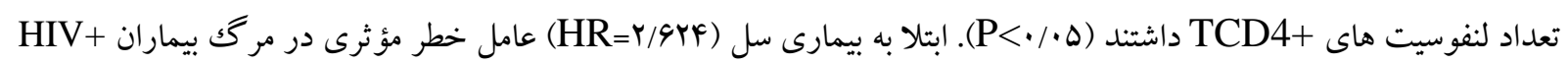

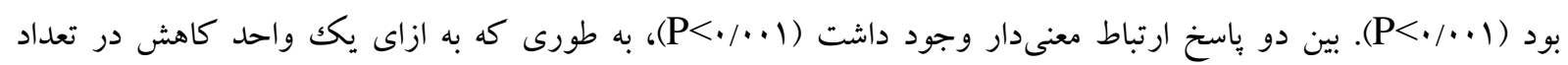

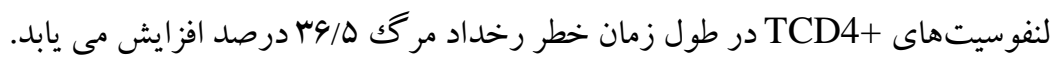

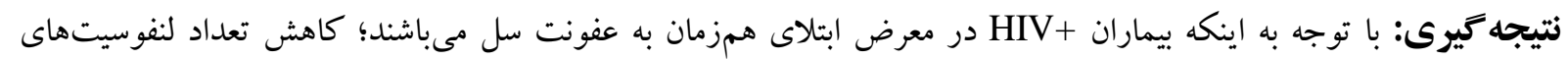
مCD4+

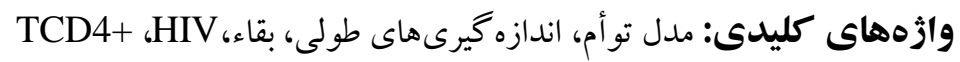

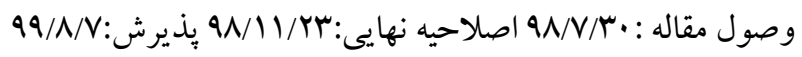


HIV/AIDS قابل كنترل است(A). افراد مبتلا به HIV بيشتر از ساير افراد مستعد عفونتهاى فرصت طلب، به ويزه عفونت همزمان

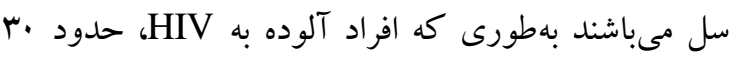

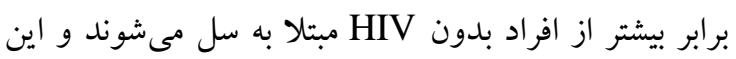

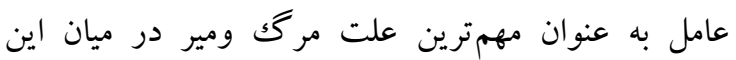

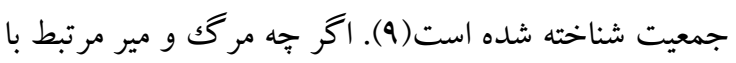
در سالهاى اخير كاهش يافته است. دركك بهتر عوامل مؤثر نظير شاخصهاى آزمايشگاهى و بالينى بر بقاى بيماران

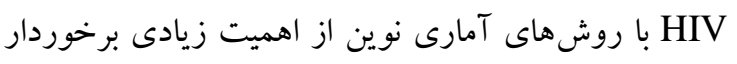
است. به ويزه در كشورهاى درحال توسعه كه مطالعات

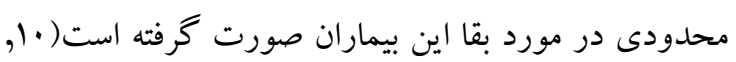
9, (1). ازجمله روشهاى نوين ميتوان به مطالعه همزمان بقا و مدل بندى دادههاى طولى اشاره نمود. در بسيارى از

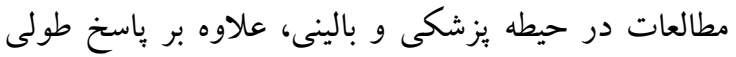

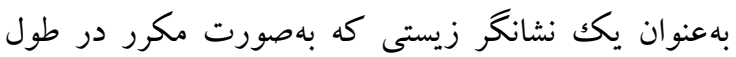
زمان اندازه گيرى مىشود؛ زمان سبرى شده تا وقوع رويداد مورد بررسى در كنار هم جمع آورى مىشوند (11). در اين شرايط جنانجه دو فر آيند طولى و بقا به يكديخر وابسته باشند، تحليل مجزاى آنها ممكن است به دليل در نظر نخرفتن ساختار همبستخى بين دو باسخ منجر به بر آوردهاى اريب شود. بهطورى كه در مطالعهاى با استفاده از شبيه سازى نشان داده شده است، وقتى همبستكى بين دادههاى طولى و بقا معنىدار باشد، با تحليل مجزاى دادهها ميانهى زمان بقاى افراد حدود ينجاه درصد كمتر برآورد مىشود(Y)). در كذشته از روشهايى از جمله مدل كاكس

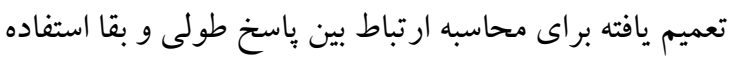

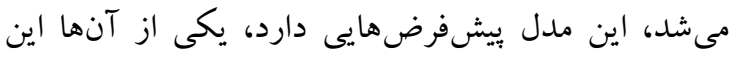
است كه متغير هاى كمكى مى بايست برون زاد(External)

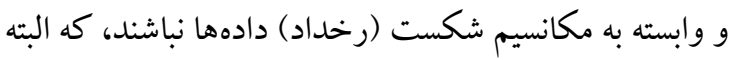

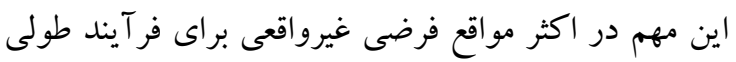

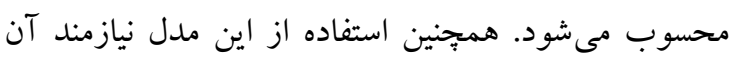
است كه مقدار هر متغير كمكى در هر نقطه زمانى كه هـ
مقدمه ويروس نقص سيستم ايمنى انسانى (HIV) همجِنان يك

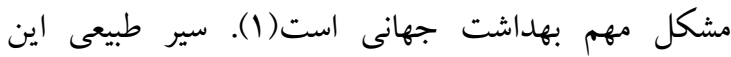
عفونت، شامل مراحل عفونت حاد HIV، دوره بدون علامت و ابتلا به ايدز است، كه بر اساس سيستم طبقهبندى

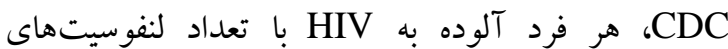

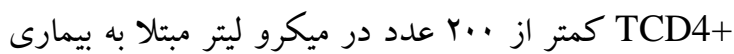

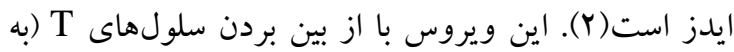

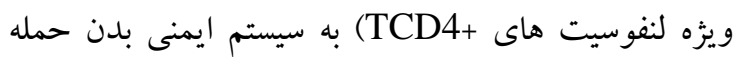

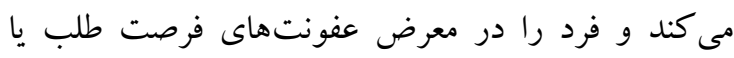
برخى از سرطانهاى مرتبط قرار مىدهد كه اين نشانهاى از ورود به مرحله ايدز به عنوان آخرين مرحله عفونت

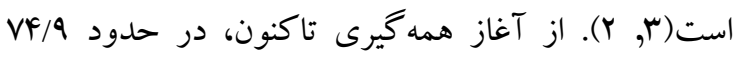

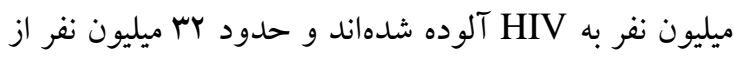
آنها به دلايل مرتبط با ايدز فوت كردهاند. در بايه لهان سال

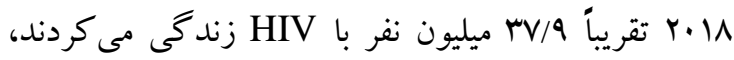

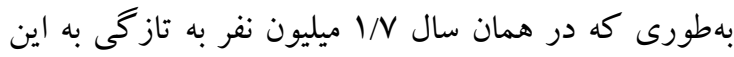
ويروس در سطح جهان آلوده شده بودند(F). طبق كزارش سازمان بهداشت جهانى در ايران شيوع بيمارى ايدز در حال افزايش است به طورى كه در گروههاى برخطر به بيش از

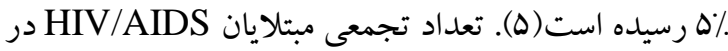

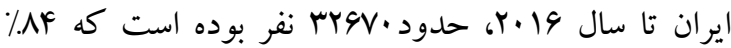
مرد و 19٪ زن بودهاند(9). با اين وجود هيج درمان قطعى براى عفونت HIV وجود ندارد، درمان ضد رتروويروسى مى تواند ييشرفت ويروس HIV را به طور مؤثر كنترل كند و

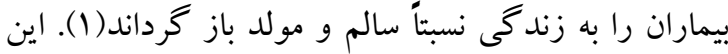
روش درمانى ميزان بقا و عملكرد سيستم ايمنى بدن را براى كسانى كه با HIV/AIDS زند و با كاهش بارهاى ويروسى مىتواند انتقال HIV را كاهش

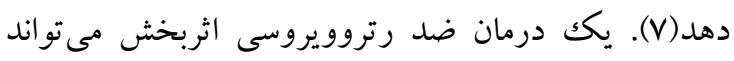

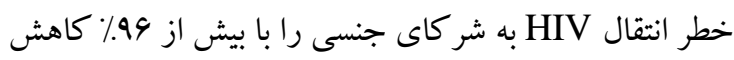
بار ويروسى كاهش دهد(Y). از طرف ديخر، هدف اصلى درمان ضد رتروويروسى طولانى كردن زندگى، و و تبديل 
مركز در نظر گرفته شد. سانسور شدگى از راست شامل

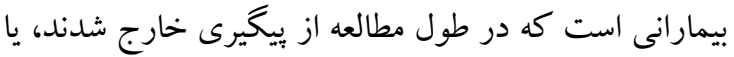

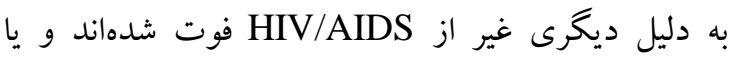
افرادى كه تا يايان دوره مطالعه زنده بودهاند. روش آمارى در مطالعه حاضر از مدل توأم با استفاده از رويكرد يارامتر

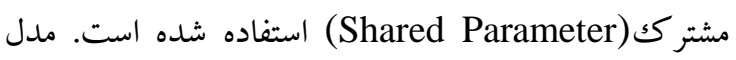
هاى تو أم با ادغام دو زير مدل طولى و بقا و در نظر گرفتن تمام اطلاعات به طور همزمان، استنتاج هاى معتبر و كار آمد ودي

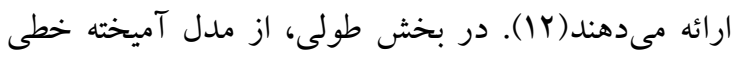

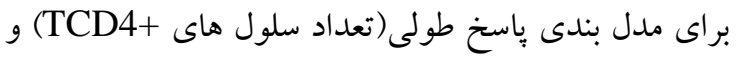

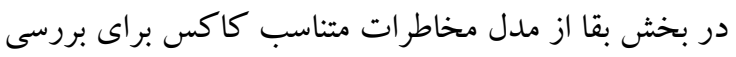

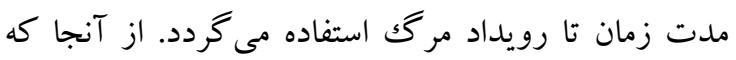
TCD4+ داراى جولكى بود از تبديل ريشه دوم آن استفاده

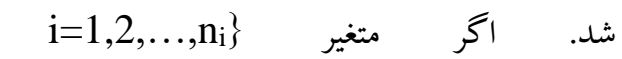
الندازههاى(مقادير) $\quad$ تكرارى باسخ لا براى فرد أام باشد؛ مدل آميخته خطى براى مقادير TCD4+ تبديل شده به شرح زير است (معادله ): $\left\{\begin{array}{c}\mathrm{yi}(\mathrm{t})=\mathrm{X}_{\mathrm{i}}(\mathrm{t}) \beta+\mathrm{Z}_{\mathrm{i}}(\mathrm{t}) \mathrm{b}_{\mathrm{i}}+\varepsilon_{\mathrm{i}}(\mathrm{t}) \\ \mathrm{b}_{\mathrm{i}} \sim \mathrm{N}(0, \mathrm{D}) \\ \varepsilon_{\mathrm{i}}(\mathrm{t}) \sim \mathrm{N}\left(0, \sigma^{2}\right)\end{array}\right.$

كه در آن yil مقدار باسخ طولى اندازه

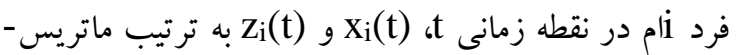
هاى متغيرهاى كمكى فرد أام متناظر با هر كدام از اثرات ثابت و تصادفى مىباشند. بردار اثرات تصادفى bi كه داراى توزيع نرمال با بردار ميانگين صفر و D ماتريس واريانس بردات كواريانس است از اثرات ثابت و تصادفى به ترتيب، براى بررسى اثر ساير

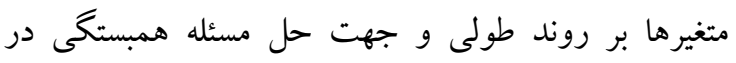

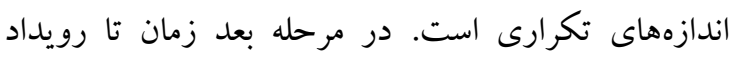

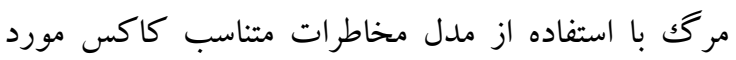

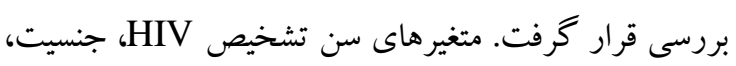

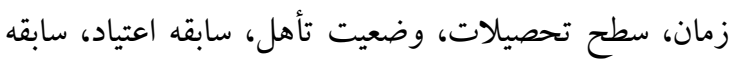

رويداد رخ داده است، براى تمامى افراد معلوم باشد. اين

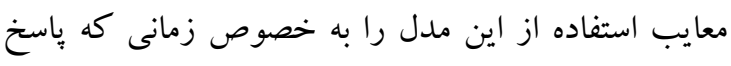

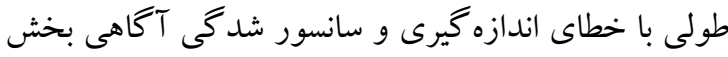

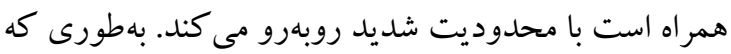
محققان به سمت روشهاى جديدتر نظير مدل هاى توأم

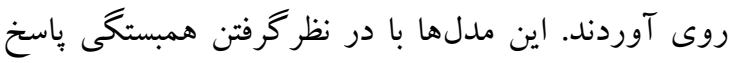

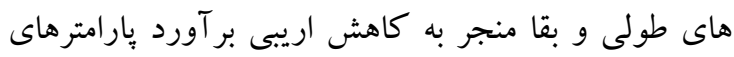

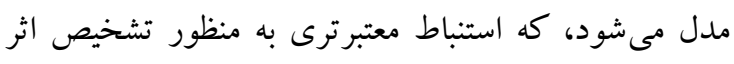

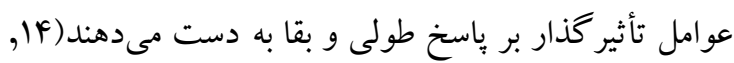
rا). اين مطالعه با هدف تعيين همزمان عوامل مؤثر بر تغيير تعداد لنفوسيت هاى TCD4 و بقاى بيماران مبتلا به HIV با مدلسازى تو أم اندازه گيرى هاى طولى و بقا انجام شد.

\section{مواد و روشها} جامعه آمارى در اين مطالعه بر اساس اطلاعات هم گرخاوهى

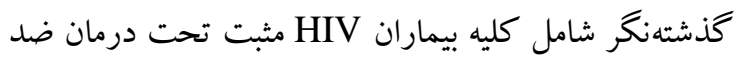

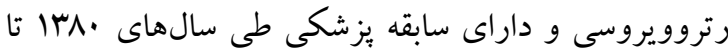

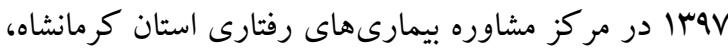
مبتنى بر ريجسترى الكترونيكى بود. نتيجه مثبت بودن HIV

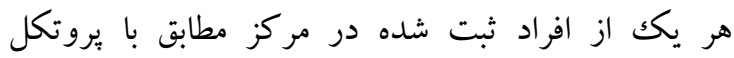
كشورى با استفاده تست تشخيصى سريع Rapid) Dو كيت متفاوت الايزاى نسل جهارم Diagnostic Test) مورد تائيد آزمايشگاه مرجع سلامت، محرز شده بود(ه) (1). دادها از يرونده شامل: عدم بارارى، داراى حداقل دو مقدار TCD4+Tك، سن بيشتر از يكك سال، با استفاده از جكك ليست جمع آورى شد. كه با توجه به اطلاعات مستند شده در سوابق بز شكى، شامل اطلاعات دمو گرافيك (سن تشخيص HIV، جنسيت، وضعيت تأهل و سطح تحصيلات)، اطلاعات رفتارى (سابقه اعتياد/ سابقه رفتار غير ايمن جنسى)، تعداد سلول-

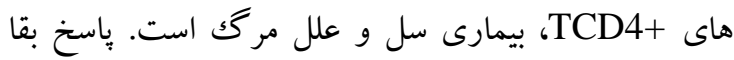

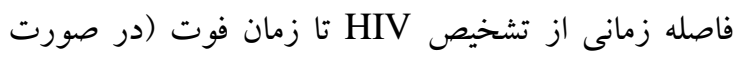

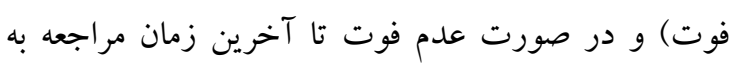


طول مطالعه بود. در اين مطالعه ميانه مدت زمان بيخيرى

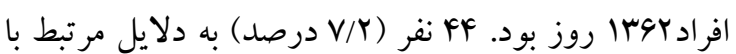
HIV/AIDS براى يك نمونه تصادفى از •ا بيمار در طول (TCD4+) زمان ارائه شده است (نمودار (1). با توجه به اينكه اندازهكيرىهاى مكرر(TCD4) داراى عرض از مبدأ و روند تصادفى در طول زمان بودند؛ بنابر اين از مدل اثرات آميخته

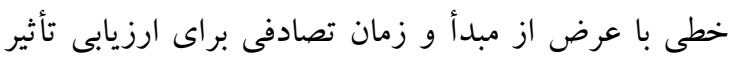
عوامل مختلف بر تغيير تعداد لنفوسيت هاى TCD4+

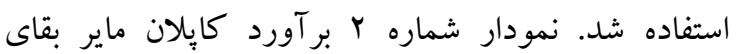

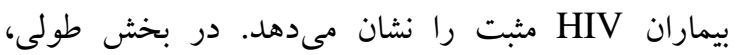
مىتوان تأثير معنىدار متغيرهاى جنسيت، سن تشخيص، وضعيت تأهل، سابقه اعتياد، سطح تحصيلات، بيمارى سل و و زمان در طول مطالعه بر تعداد لنفوسيتهاى TCD4+

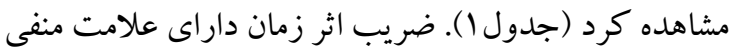
است كه نشان مىدهد به طور متوسط تعداد سلولهاى TCD4+ با كذشت زمان كاهش مى يابد (1/.1 (P<). بر آورد متوسط ضريب رگرسيون طولى براى جنسيت منفى و به طور معنىدار با صفر متفاوت است، نشان مىدهد كه بيماران مرد تعداد سلولهاى TCD4 كمترى نسبت به زنان

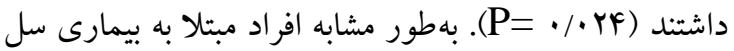

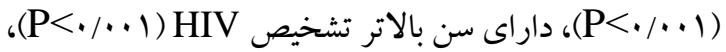

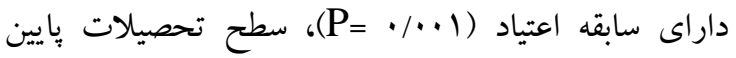

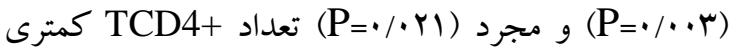
در طول مطالعه داشتند؛ و سابقه رفتار غير ايمن جنسى تأثير معنى بخش بقا، افراد با بيمارى سل داراى خطر نسبى مرگكومير تعراي T/GYF برابر نسبت به افراد بدون بيمارى سل بودند

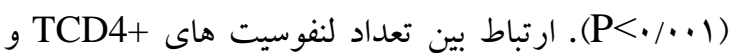

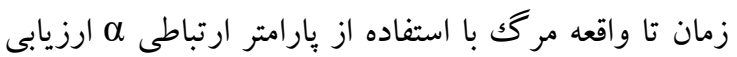

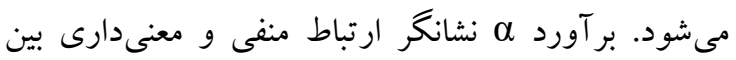

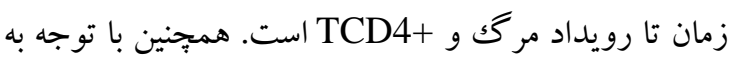
نسبت خطر بر آورد شده (exp(
رابطه غير ايمن جنسى، بيمارى سل، در هر دو فر آيند طولى (ريشه دوم تعداد +TCD4) و فرآيند بقا در نظر گرفته شدند. ابتدا متغيرها بهصورت تكى وارد زير مدلها شدند و معنى دارى اثر متغيرها در اين مدلهاى مجزا بررسى گرديد. از آنجا كه مقدار +TCD4 وابسته به زمان است و مقدار آن در بين زمانهاى ويزيت ثابت نيست در مرحله آخر، مدل

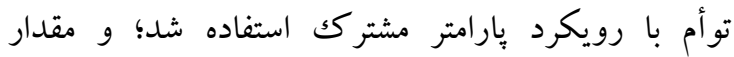

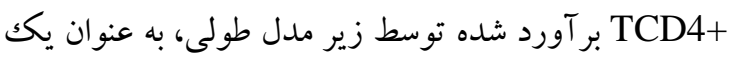

متغير وابسته به زمان در مدل بقا قرار مى گيرد (معادله Y): $\mathrm{h}_{\mathrm{i}}\left(\mathrm{t} \mid \mathrm{M}_{\mathrm{i}}(\mathrm{t}), \mathrm{w}_{\mathrm{i}}\right)=\mathrm{h}_{0}(\mathrm{t}) \exp \left\{\gamma^{\mathrm{T}} \mathrm{W}_{\mathrm{i}}+\alpha \mathrm{m}_{\mathrm{i}}(\mathrm{t})\right\}$

نشان دهندهى تاريخجه $M_{i}(t)=\left\{m_{i}(s), 0 \leq s<t\right\}$ فر آيند طولى مشاهده نشدهى واقعى تا زمان t است. Wi بردار

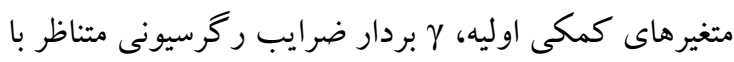
آن است، ه بردار ارتباط بين اندازه گيرىهاى مكرر تا زمان

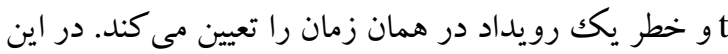
مطالعه يكك مدل توأم با روش برآورد حداكثر درستنمايى به كار گرفته شد. دادهها با استفاده از نرم افزار (3.2.0) بسته JM تجزيه و تحليل شدند (19, rا).

\section{يافته ها}

از Flf فرد آلوده به HIV، TVD نفر مبتلا به بيمارى ايدز

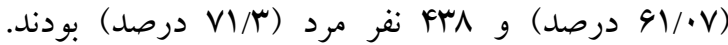

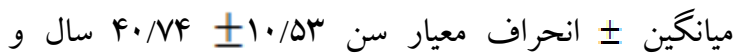
ميانگين \pm انحراف معيار سن تشخيص HIV، 1.91

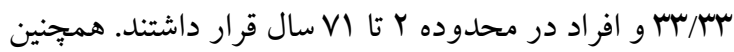

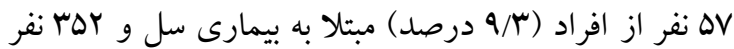

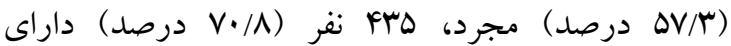
تحصيلات زير دييلم، HVF نفر (9.9 درصد) سابقه اعتياد و هو نفر (هq/9 درصد) داراى سابقه رفتار غير ايمن جنسى بودند. در مجموعه دادههاى ما MYFY مشاهده اندازههاى تكرارى در طول زمان براى +TCD4 ثبت شد. حداقل و

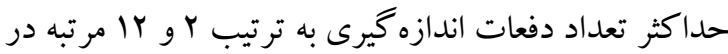


توان كفت به ازاى يكك واحد كاهش در لنفوسيتهاى ارتباط قوى بين دو پياسخ طولى و بقا و از سوى ديخر

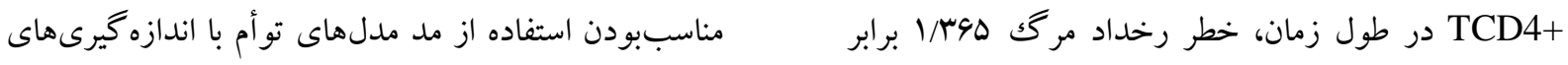

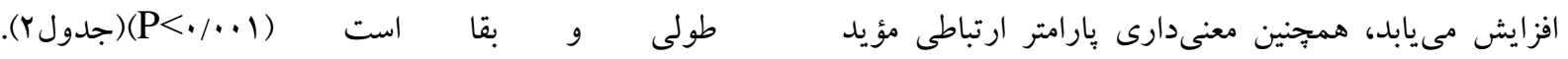

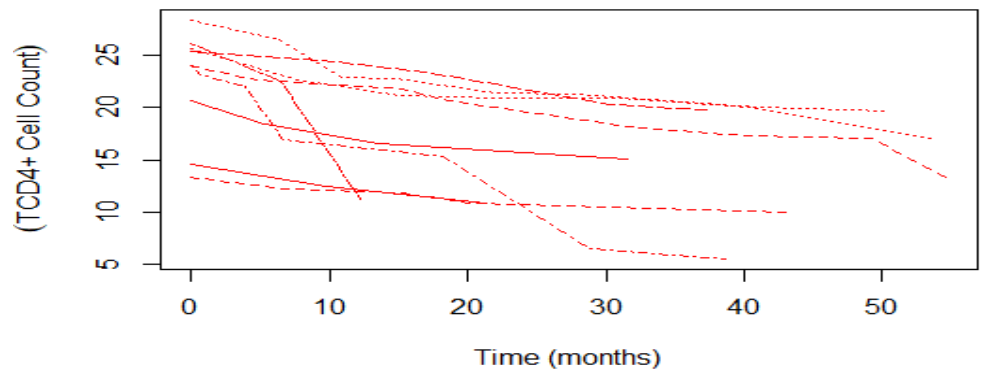

نمودار ا. روند طولى لنفوسيت TCD4 يك نمونه تصادفى • ا نفرى بيماران HIV+

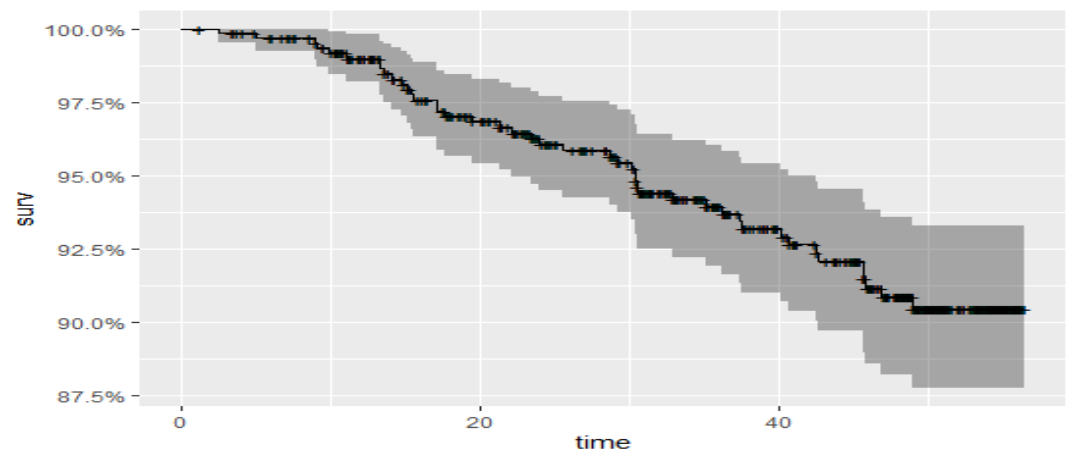

HIV+ نمودار T. نمودار كايلان ماير بقاى بيماران

جدول ا. نتايج برازش مدل توأم با اندازهكيرىهاى طولى و بقا

\begin{tabular}{|c|c|c|c|c|c|}
\hline نسبت خطر & مقدارP & خطاى معيار & ضريب & متغير (سطح اصلى) & مدل \\
\hline $1 / \cdot r r$ &.$/ 11 r$ &.$/ .10$ & /.rr & سن تشخيص & \multirow{6}{*}{ زير مدل بقا } \\
\hline 1/OVG &.$/ 491$ & $\cdot / A+1$ & $\cdot / 4 \Delta \Delta$ & سطح تحصيلات(زير دييلم) & \\
\hline I/IFV & $\cdot|A Y|$ &.$/ 914$ &.$/ M$ & جنسيت(مرد) & \\
\hline $1 / f \Delta V$ & • & $\cdot / r V r$ & $\cdot / r V V$ & وضعيت تأهل(مجرد) & \\
\hline ./VAS &. IGFF & . /Or. & $-\cdot / Y F$ & سابقه اعتياد(دارد) & \\
\hline Y/GYF & $<\cdot / \cdot 1$ & $\cdot / r 4 q$ &.$/ 990$ & بيمارى سل(دارد) & \\
\hline- & $<\cdot / \cdot \cdot 1$ & .1 .94 & $-\cdot / Y Y F$ & زمان & \multirow{6}{*}{ زيرمدل طولى } \\
\hline- & $<\cdot / \cdots)$ & $\cdot / \cdot \mathrm{rF}$ & $-\cdot / 109$ & سن تشخيص & \\
\hline- & $\cdot / \cdot Y F$ & $\cdot / A Y V$ & $-1 / \wedge G Y$ & جنسيت(مرد) & \\
\hline- & $\cdot / \cdot r$ & $\cdot / \Delta V r$ & $-1 / 991$ & سطح تحصيلات(زير دييلم) & \\
\hline- & $\cdot / \cdot r \mid$ & $\cdot / D F A$ & $-1 / Y \Delta \Lambda$ & وضعيت تأهل(مجرد) & \\
\hline- & $\cdot / \cdots 1$ &.$/ V 90$ & $-r / \Delta 1$ & سابقه اعتياد(دارد) & \\
\hline
\end{tabular}

هجلم علمى دانشكاه علوه يِشكى كردستان / دوره بيست و شش / دهر و آبان م.ع|| 


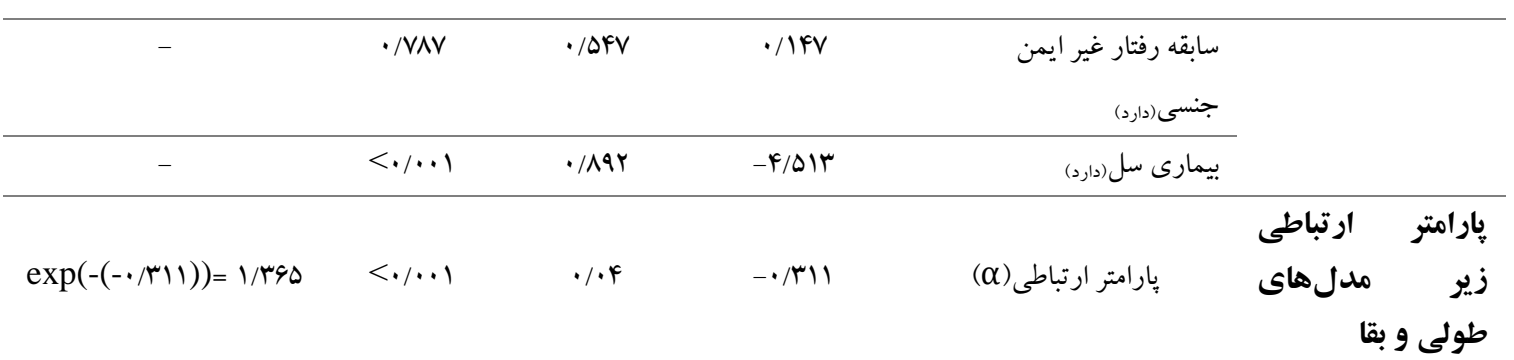

إييدميولوزيك نشان دادهاند كه با كاهش شمارش سلول خطر ابتلا به عفونت همزمان سل و اج ایى وى TCD4+ افزايش مىيابد(YN, YN). در بسيارى از مطالعات در مورد

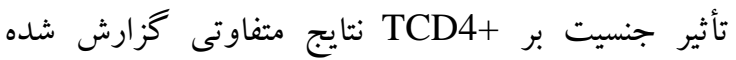

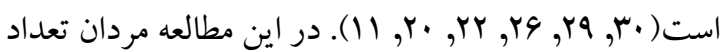

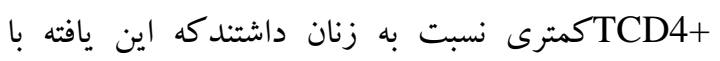

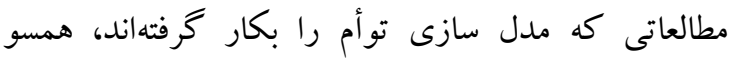
مىباشند(r, ب, (1) و با نتايج مطالعه Adams و همكاران

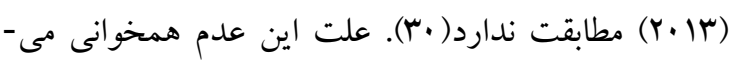

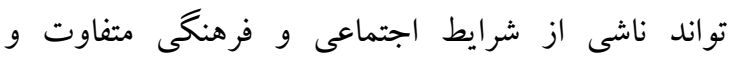

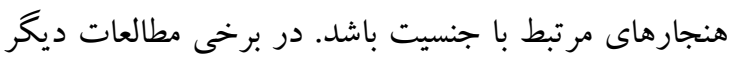

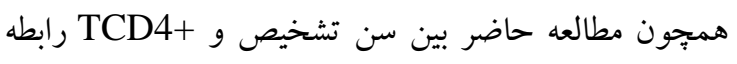

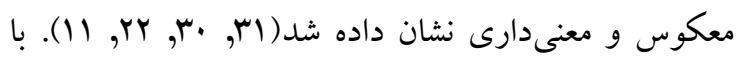

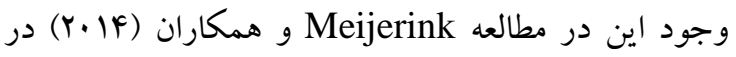
كشور هلند، ارتباط بين سن بيمار و كاهش شرد شديد تعداد

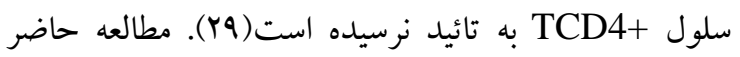
ارتباط معنىدارى بين سطح تحصيلات بايين و كاهش سلول+TCD4 مشاهده شد اين يافته در توافق با مطالعه

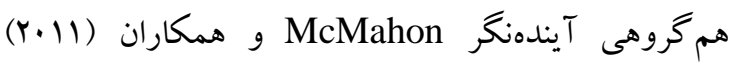
است(Yr). در مطالعه حاضر افراد با سابقه اعتياد، تعداد لنفوسيت هاى TCD4+ كمترى داشتند اين يافته با مطالعه Meijerink آميخته انجام شد در توافق است(Yq). يافتهاى ما نشان داد كه افراد HIV مثبت كه به بيمارى سل مبتلا شدهاند، دو برابر بيشتر در مقايسه با كسانى كه فقط مبتلا به HIV بودند،

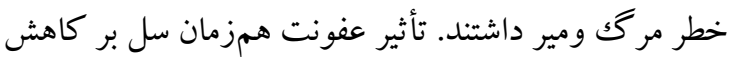
بقاى بيماران HIV+ در بسيارى از مطالعات به تائيد رسيده
مدل تو أم با اندازهيرىهاى طولى و بقا يكك ابزار آمارى

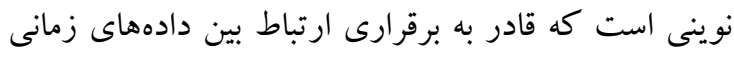

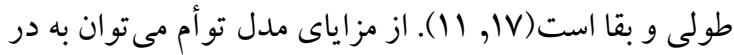
نظر گرفتن سانسور شدگى آكاهى بخش؛ كه ناشى از نبود مشاهدات بين زمانهاى وقوع رويداد است، كاهش اريبى بر آوردها ( با محاسبه خطاى اندازه گيرى) و همجينين افزايش كارايى آمارى با به كار گيرى همزمان تمامى دادهها تنها در

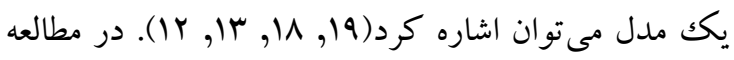

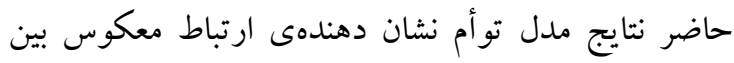

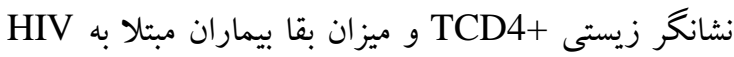

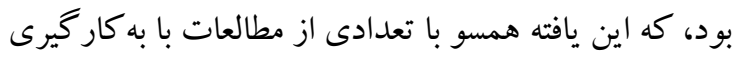

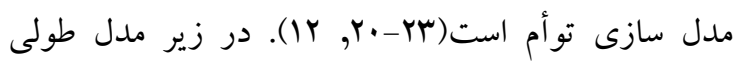

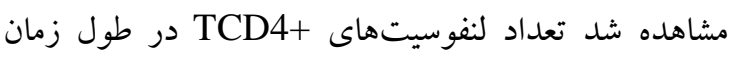

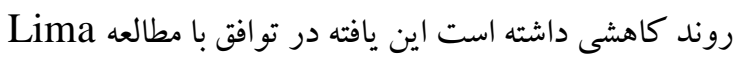

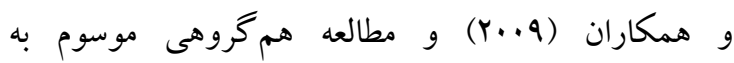
CASCADE كه بروى بيماران HIV مثبت در ايتاليا به وركيه منظور بررسى تأثير+TCD4 بعد از رواج درمان ضد بدوب

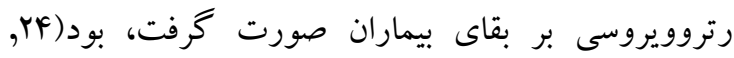

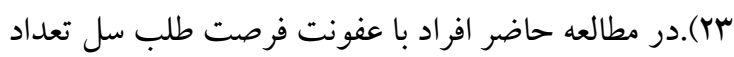
لنفوسيتهاى TCD4+ كمترى نسبت به افراد فقط مبتلا HIV

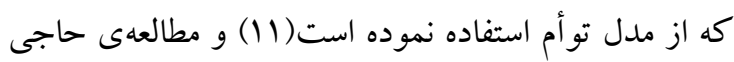

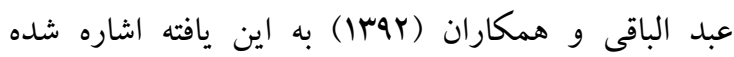

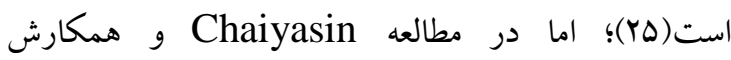
(Y.19)در كشور تايلند اثر عفونتهاى همزمان بر كاهش TCD4+ معنى Tار نبود(Y)). علاوه بر اين، برخى مطالعات 
در مدل توأم ارتباط معنىدار آمارى بين متغيرهاى جنسيت، سن تشخيص، وضعيت تأهل، سابقه اعتياد، سطح تحصيلات، بيمارى سل و زمان در طول مطالعه با تغيير تعداد لنفوسيتهاى TCD4 مشاهده شد. با توجه به رابطه معكوس نشان داده شده بين لنفوسيتهاى TCD4+ و خطر مر گكومير در اثر HIV/AIDS در اين مدل بندى توأم، كاهش تعداد سلولهاى TCD4+ در طول زمان نشانگر مناسبى براى بررسى روند بيمارى و تعيين رخداد مرگك در اين بيماران خواهد بود. از محدوديت هاى اين مطالعه مشخص نبودن افراد مبتلا به ايدز بود و اطلاعات كليه افراد مورد بررسى صرفاً بهعنوان بيماران HIV مثبت در اختيار محققين قرار كرفته بود.

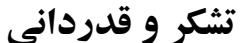
مقاله حاضر بخشى از نتايج پاياننامه كارشناسى ارشد رشته آمار زيستى با حمايت مالى معاونت تحقيقات و فناورى

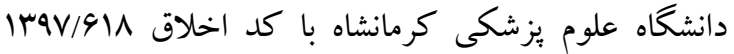
است. نويسند كان مقاله مراتب تشكر و قدردانى خود را از همكارى كميته تحقيقات دانشجويى دانشكاه علوم يزشكى و مركز مشاوره بيمارى هاى رفتارى استان كرمانشاه، اعلام

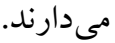

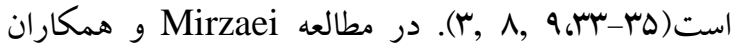

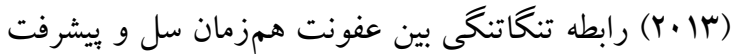

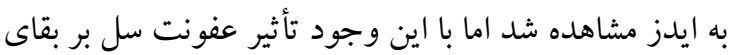
بيماران معنىدار تشخيص داده نشد، علت اين عدم همخوانى

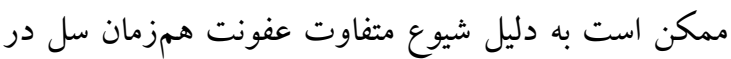

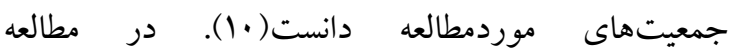
Momenyan و همكاران (Y. ا ( افراد HIV مثبت كه به بيمارى سل مبتلا شدهاند، دو برابر بيشتر خطر ابتلا به ايدز

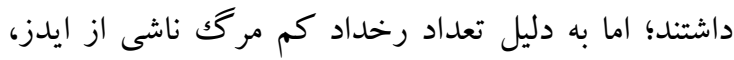
ارتباطى بين عفونت همزمان سل و مركى ناشى از ايدز

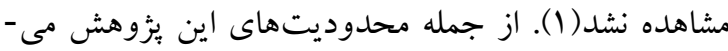

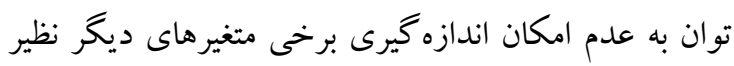

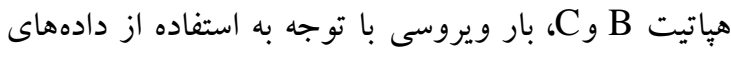
ثبت شده در ريجسترى اشاره نمود كه بيشنهاد مى شود در

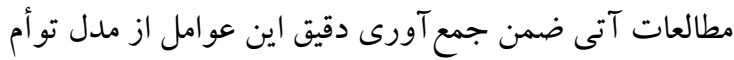

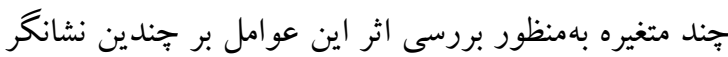
زيستى طولى (مانند TCD4 و بار ويروسى) و همجِين بقاى اين بيماران بهره گرفت. نتيجه كيرى

1.Momenyan S, Yadegarfar M, Meshkati M, Tayeri K, Yadegarfar G. Predictors of HIV Progression to AIDS and Mortality from AIDS and Non-AIDS Related: A Retrospective Cohort Study in Isfahan, Iran. J AIDS Clin Res. 2017;8(8): 1-8.

2.Centers for Disease Control and Prevention. About HIV/AIDS. CDC website. Available from: https://www.cdc.gov/hiv/basics/whatishiv.html .Published october 5, 2019.

3.Hamidi O, Poorolajal J, Tapak L. Identifying predictors of progression to AIDS and mortality post-HIV infection using parametric multistate model. EBPH. 2017;14(2). 1-9

4.UN AIDS. Fact sheet september 2019. UN AIDS website. Available from: https://www.unaids.org/en/resources/fact-sheet. Published september 2019.

5.Haghdoost AA, Mostafavi E, Mirzazadeh A, Navadeh S, Feizzadeh A, Fahimfar N, et al. Modelling of HIV/AIDS in Iran up to 2014. J AIDS Clin Res. 2011;3(12): 231-239.

6.Lotfi MH, Khajeh M, Pedarzadeh M, Jafarzadeh M, Pourmazar A, Sharifi M, et al. Epidemiology and Trend of HIV/AIDs in Yazd, A Province in the Center of Iran, 2011-2017. JCHR. 2018; 7( 4): 214-221. 
7.Bajpai RC, Raj P, Jha UM, Chaturvedi HK, Pandey A. Demographic correlates of survival in adult HIV patients registered at ART centers in Andhra Pradesh, India: a retrospective cohort study. Public Health Res. 2014;4(1): 31-38.

8.Biset Ayalew M. Mortality and its predictors among HIV infected patients taking antiretroviral treatment in ethiopia: a systematic review. AIDS Res Trea. 2017;2017: 1-10.

9.Poorolajal J, Molaeipoor L, Mohraz M, Mahjub H, Ardekani MT, Mirzapour P, et al. Predictors of progression to AIDS and mortality post-HIV infection: a long-term retrospective cohort study. AIDS care. 2015;27(10): 1205-1212.

10.Mirzaei M, Poorolajal J, Khazaei S, Saatchi M. Survival rate of AIDS disease and mortality in HIV-infected patients in Hamadan, Iran: a registry-based retrospective cohort study (1997-2011). Int J STD AIDS. 2013;24(11): 859-866.

11.Erango MA, Goshu AT, Buta GB, Dessiso AH. Bayesian joint modelling of survival of HIV/AIDS patients using accelerated failure time data and longitudinal CD4 cell counts. $\mathrm{Br} \mathbf{J}$ Med Med Res. 2017;20(6): 1-12.

12.Guo X, Carlin BP. Separate and joint modelling of longitudinal and event time data using standard computer packages. Am Stat. 2004;58(1): 16-24.

13.Rizopoulos D. Joint models for longitudinal and time-to-event data: With applications in R: Chapman and Hall/CRC; 2012: 55-63

14.Ebrahimzadeh F, Hajizadeh E, Baghestani A, Nasseryan J. Timing the incidence of restenosis and some effective factors in patients undergoing angioplasty using extended cox regression model. J. Mazandaran Univ Med Sci. 2017;26(146): 56-67.

15.Samiei S TK, Abasian L, mohrez M, Namdari H. HIV treatment counseling and diagnostic Country guidelines. In: Health Mo, editor.Department of Health and Medical Education, 2017: 30-34

16.Rizopoulos D JM: An R package for the joint modelling of longitudinal and time-to-event data. J Stat Softw. 2010;35(9): 1-33.

17.Temesgen A, Gurmesa A, Getchew Y. Joint Modeling of Longitudinal CD4 Count and Time-to-Death of HIV/TB Co-infected Patients: A Case of Jimma University Specialized Hospital. ADS. 2018;5(4): 659-678.

18.Gilani N, Kazemnejad A, Zayeri F, Hadaegh F, Azizi F, Khalili D. Anthropometric indices as predictors of coronary heart disease risk: Joint modeling of longitudinal measurements and time to event. Iran J Public Health. 2017;46(11): 1546-1554.

19.Ibrahim JG, Chu H, Chen LM. Basic concepts and methods for joint models of longitudinal and survival data. J Clin Oncol. 2010;28(16): 2796-2801.

20.Lim HJ, Mondal P, Skinner S. Joint modeling of longitudinal and event time data: application to HIV study. J Med Stat Inform. 2013;1(1): 1-9.

21.Chen Q, May RC, Ibrahim JG, Chu H, Cole SR. Joint modeling of longitudinal and survival data with missing and left-censored time-varying covariates. Statist Med. 2014;33(26): 4560-4576.

22.Grover G, Swain P, Deo V, Varshney M. A Joint Modeling Approach to Assess the Impact of CD4 Cell Count on the Risk of Loss to Follow up in HIV/AIDS Patients on Antiretroviral Therapy. Int J Stat Appl. 2015;5(3): 99-108.

23.Brombin C, Di Serio C, Rancoita PM. Joint modeling of HIV data in multicenter observational studies: A comparison among different approaches. Stat Methods Med Res. 2016;25(6): 2472-2487. 
24.Lima VD, Fink V, Yip B, Hogg RS, Harrigan PR, Montaner JS. Association between HIV1 RNA level and CD4 cell count among untreated HIV-infected individuals. Am J Public Health. 2009;99(S1): 193-196.

25.Hajiabdolbaghi M, Jafari S, Alijani N, Hedayat-Yaghoobi M. Prevalence of Opportunistic Infections among Hospitalized Patients with HIV/AIDS in Tehran Imam Khomeini Hospital (Iran), during 2009-2012. J Isfahan Med Sch. 2014;31(266): 1-5.

26.Chaiyasin N, Sungkanuparph S. Rate of CD4 decline and factors associated with rapid CD4 decline in asymptomatic HIV-infected patients. J Int Assoc Provid AIDS Care. 2016;15(1): 3-6.

27.Hwang J-H, Choe PG, Kim NH, Bang JH, Song K-H, Park WB, et al. Incidence and risk factors of tuberculosis in patients with human immunodeficiency virus infection. J Korean Med Sci. 2013;28(3): 374-377.

28.Molaeipoor L, Poorolajal J, Mohraz M, Esmailnasab N. Predictors of tuberculosis and human immunodeficiency virus co-infection: a case-control study. Epidemiol Health. 2014;36: 1-6.

29.Meijerink H, Wisaksana R, Iskandar S, den Heijer M, van der Ven AJ, Alisjahbana B, et al. Injecting drug use is associated with a more rapid CD4 cell decline among treatment naïve HIVpositive patients in Indonesia. J Int AIDS Soc. 2014;17(1): 18444-18450.

30.Adams M, Luguterah A. Longitudinal analysis of change in CD4+ cell counts of HIV-1 patients on antiretroviral therapy (ART) in the Builsa district hospital. ESJ. 2013;9(33): 299309.

31.Li X, Margolick J, Jamieson B, Rinaldo C, Phair J, Jacobson L. CD4+ T-cell counts and plasma HIV-1 RNA levels beyond 5 years of highly active antiretroviral therapy (HAART). J Acquired Immune Defic. Syndr. 2011;57(5): 421-428.

32.McMahon J, Wanke C, Terrin N, Skinner S, Knox T. Poverty, hunger, education, and residential status impact survival in HIV. AIDS Behav. 2011;15(7): 1503-1511.

33.Lopez-Gatell H, Cole SR, Margolick JB, Witt MD, Martinson J, Phair JP, et al. Effect of tuberculosis on the survival of HIV-infected men in a country with low TB incidence. AIDS. 2008;22(14): 1869-1873.

34.Badri M, Ehrlich R, Wood R, Pulerwitz T, Maartens G. Association between tuberculosis and HIV disease progression in a high tuberculosis prevalence area. INT J TUBERC LUNG DIS. 2001;5(3): 225-232.

35. Whalen CC, Nsubuga P, Okwera A, Johnson JL, Hom DL, Michael NL, et al. Impact of pulmonary tuberculosis on survival of HIV-infected adults: a prospective epidemiologic study in Uganda. AIDS. 2000;14(9): 1219-1228. 